\title{
Ten Principles of Good Business Process
}

\section{Management}

This is the author's version of a work that was

submitted/accepted for publication in the following source:

vom Brocke, J., Schmiedel, T., Recker, J., Trkman, P., Mertens, W., \& Viaene, S. (2014). Ten Principles of Good Business Process Management. Business Process Management Journal (BPMJ)

Notice: Changes introduced as a result of publishing processes such as copy-editing and formatting may not be reflected in this document. For a definitive version of this work, please refer to the published source. 


\title{
Ten Principles of Good Business Process
}

\section{Management}

\begin{abstract}
Purpose - The purpose of this paper is to foster a common understanding of business process management (BPM) by proposing a set of ten principles that characterize BPM as a research domain and guide its successful use in organizational practice.
\end{abstract}

Design/methodology/approach - The identification and discussion of the principles reflects our viewpoint, which was informed by extant literature and focus groups, including 20 BPM experts from academia and practice.

Findings - We identify ten principles which represent a set of capabilities essential for mastering contemporary and future challenges in BPM. Their antonyms signify potential roadblocks and bad practices in BPM. We also identify a set of open research questions that can guide future BPM research.

Research limitation/implication - Our findings suggest several areas of research regarding each of the identified principles of good BPM. Also, the principles themselves should be systematically and empirically examined in future studies.

Practical implications - Our findings allow practitioners to comprehensively scope their BPM initiatives and provide a general guidance for BPM implementation. Moreover, the principles may also serve to tackle contemporary issues in other management areas.

Originality/value - This is the first paper that distills principles of BPM in the sense of both good and bad practice recommendations. The value of the principles lies in providing normative advice to practitioners as well as in identifying open research areas for academia, thereby extending the reach and richness of BPM beyond its traditional frontiers.

Keywords principles, business process management, BPM, research agenda

Paper type Viewpoint 


\section{Introduction}

Business process management (BPM) has evolved as an important research domain that has matured considerably. It provides well-proven methods that build the foundation to master current and future challenges in management. However, the adoption and use of BPM remains fragmented and there is little agreement concerning the right scoping of BPM (Rosemann and vom Brocke, 2010). Although researchers call for a comprehensive approach to BPM (Rosemann and de Bruin, 2005; Viaene et al., 2010) both in academia and practice, BPM has largely remained focused on originating areas such as process modeling and workflow management systems or on identifying case- or industry-specific and general critical success factors (CSFs) of BPM programs (van der Aalst et al., 2003; Jeston and Nelis, 2008). Although CSFs of BPM, defined as a few things that must function well to assure success (Boynton and Zmud, 1984), may provide relevant ideas for practitioners, most CSF studies conclude by presenting a list of general factors (e.g., top management support, communication, appropriate culture, appointment of process owners and end-user training (Ariyachandra and Frolick, 2008; Bai and Sarkis, 2013; Bandara et al., 2005; Karim et al., 2007; Trkman and Trkman, 2009)) but provide little further practical guidance (King and Burgess, 2006). Some authors attempt to provide a more detailed recommendation for the usage of CSFs. Škrinjar and Trkman (2013), for example, study which critical practices have a significant positive effect on improvement in an organization's business process orientation. They argue that there are specific and identifiable practices for each maturity level and break down previously identified critical success factors (Trkman, 2010) to very precise practices such as "Process terms such as input, output, process, and process owners are used in conversations" or "Managers from different departments regularly have meetings to discuss business process-related issues”.

While such attempts are important to provide both generic and specific guidelines for implementing BPM, they do not contribute to shaping BPM as a research domain or to providing overarching guidance for the governance of BPM programs. We believe that a focus on critical practices is too limited and that identified CSFs do not sufficiently reflect the essential principles of good BPM. Further, we have observed many cases where projects are labeled as BPM, despite the fact that they do not abide by the essential principles of BPM. In other projects, methods such as process modeling are being applied, but in too narrow a sense. This is the case, for instance, when process-modeling efforts are made with little consideration of governance structures required to leverage and maintain such models or to 
turn the results of such efforts into long-term benefits for an organization and its stakeholders. Arguably, the problems in applying BPM in practice are mirrored in scholarly work - by far the largest share of contributions to the BPM conference series to date, for instance, have been dedicated to designing, enacting or verifying process models (van der Aalst, 2012). Research that indicates a more holistic coverage of BPM issues, such as educational (Bandara et al., 2010a) or cultural dimensions (Schmiedel et al., 2013), have only emerged very recently. Against this background, we would like to share our viewpoint on principles of good BPM. This viewpoint is primarily based on opinions of BPM experts, but it also ties in with our own experience and with extant BPM literature. We set out to identify ten principles of good BPM that we hope will strengthen the core of BPM, so it can grow beyond its current boundaries, and guide BPM initiatives in practice, in order for these to live up to the promise of a holistic and sustainable transformation.

We are by no means the first to suggest guiding principles for BPM. Armistead (1996), for example, suggested a set of guiding principles 17 years ago when the concept of BPM was still in its infancy and when today's comprehensive understanding had not yet emerged. Few years later, Burlton (2001) also suggested a number of principles, yet most of these relate to "business change" and "process renewal", while none of them relate to "process management” in the sense of how to size and scope BPM in an organization. Revisiting BPM as a research domain today, we build our viewpoint on several sources, bringing together opinions of key players in the field to suggest encompassing principles of good BPM. We frame our principles as a research agenda for BPM research to identify key research questions extending the richness and reach of the current body of knowledge (Chircu et al., 2010). Our definition of the principles complements and goes beyond the BPM body of knowledge in several ways. It extends prior work on principles and definitions of business processes and BPM (Burlton, 2012; Burlton, 2001; Armistead, 1996), and deepens the discussion on a common BPM body of knowledge (ABPM, 2009). Our work also provides a possible answer to the call for a comprehensive consideration of BPM including organizational and social factors (Rosemann and de Bruin, 2005). While studies like these already provided important knowledge on which aspects to consider in BPM initiatives (vom Brocke et al., 2011), there is still a lack of knowledge on essential principles that support the right planning and coordination of BPM initiatives at a strategic level. This is where the principles intend to contribute and call for the consideration of previously less-covered concepts in various application domains. 
Thus our purpose for establishing these ten principles is to assist both researchers and practitioners towards an understanding of the requirements of effective BPM. Following Klein and Myers (1999) and Hevner et al. (2004), we advise against compulsory or mere routine use of the principles. Readers must use their experience and judgment to apply the principles in light of the requirements of a specific BPM program.

We proceed as follows: In the next section, we present the ten principles and discuss each principle relating to seminal work in the respected field. We then discuss the implications for research and practice. Finally, we conclude with a summary and outlook on future work.

\section{Ten Principles of Good BPM}

We build on expert opinions and focus groups to identify principles that characterize successful BPM practice. These focus groups involved 20 BPM experts from practice and academia. Specifically, ten academics and ten practitioners were invited to the focus groups. In order to integrate a complete range of viewpoints, we involved researchers in the BPM domain from four universities worldwide and from diverse positions: three full professors, one assistant professor, two $\mathrm{PhD}$ post-graduates, and four $\mathrm{PhD}$ students. The practitioners were managers in the area of BPM who, in turn, represented eight global companies from diverse industries: one from the automotive industry, two from banking, two from construction, two from engineering, one from healthcare, and two from logistics. We took the following eight steps with two focus groups to shape our viewpoint (these steps are explained in detail in the following paragraphs):

\section{First focus group (academics and practitioners)}

1. Shaping of joint BPM understanding

2. Identification of principles for good BPM

3. Clustering of the identified principles

\section{Second focus group (academics)}

4. Identification of a linguistic reference model for the principles

5. Formulation of a principle for each cluster based on linguistic reference model

6. Refinement of the identified principles

\section{Follow-up group reflections (practitioners)}

7. Reflection of the ten principles

8. Further refinement of the wording 
In a first focus group setting, we started off by discussing BPM as a holistic management approach with the practitioners and academics to generate a joint understanding of the main concept. We then asked each expert the open-ended question to individually identify up to three principles that he or she deemed important for successful BPM and to write them down on cards, so as not to bias ideas through discussions before-hand. We then went through all the cards and discussed how to categorize them. During this process, we identified nine idea categories for principles of good BPM.

In a second focus group setting, the academics formulated principles based on the identified idea categories. To do so, we first defined a linguistic reference model, i.e. how the principles should generally be formulated. We decided that the meaning of each principle should be specified considering both positive and negative statements. This approach allowed us to describe each principle in terms of its positive manifestation (i.e. a normative statement of how the principle can be realized) as well as its antonym (i.e. a normative statement of how the principle cannot be realized) (see Table 1). We then formulated principles for each idea category. Finally, we refined the principles to ensure that their content was distinct from each other.

The identified principles were first fed back to the practitioners from the first focus group to ask them for feedback. After revisions, we then included further practitioners (e.g., in executive classes and executive consulting projects) in the discussion on potential improvements regarding content or wording of the principles. Overall, more than 40 practitioners from around 10 European countries were involved at this particular stage of the process. Feedback was largely positive, with suggestions mainly focusing on wording but not on the content of the principles.

The principles solidify the state-of-the-art knowledge in BPM and, thus, may serve as a reference for further development of the field. Considering these principles, BPM can provide a solid set of capabilities essential to master contemporary and future challenges. For research, these principles are critical to further shape BPM as a research domain and at the same time prove its value for practice. Next, we present the principles in alphabetic order. Each principle is discussed in terms of its definition, its coverage in BPM research and the implications of adhering or not adhering to the principles in practice. While extant work in the field has covered at least aspects of all of the principles, we outline multiple facets of each principle and present a comprehensive overview of key guidelines to consider in BPM. 


\begin{tabular}{|c|c|c|}
\hline No. & Principle & $\begin{array}{l}\text { Description of positive manifestation }(+) \text { and antonym } \\
(-)\end{array}$ \\
\hline 1. & $\begin{array}{l}\text { Principle of Context } \\
\text { Awareness }\end{array}$ & $\begin{array}{ll}+ & \text { BPM should fit to the organizational context. } \\
- & \text { It should not follow a cookbook approach. }\end{array}$ \\
\hline 2. & Principle of Continuity & $\begin{array}{ll}+ & \text { BPM should be a permanent practice. } \\
- & \text { It should not be a one-off project. }\end{array}$ \\
\hline 3. & Principle of Enablement & $\begin{array}{ll}+ & \text { BPM should develop capabilities. } \\
- & \text { It should not be limited to firefighting. }\end{array}$ \\
\hline 4. & Principle of Holism & $\begin{array}{ll}+ & \text { BPM should be inclusive in scope. } \\
- & \text { It should not have an isolated focus. }\end{array}$ \\
\hline 5. & $\begin{array}{l}\text { Principle of } \\
\text { Institutionalization }\end{array}$ & $\begin{array}{l}+\quad \text { BPM should be embedded in the organizational } \\
\text { structure. } \\
\text { - } \quad \text { It should not be an ad-hoc responsibility. }\end{array}$ \\
\hline 6. & Principle of Involvement & $\begin{array}{ll}+ & \text { BPM should integrate all stakeholder groups. } \\
- & \text { It should not neglect employee participation. }\end{array}$ \\
\hline 7. & $\begin{array}{l}\text { Principle of Joint } \\
\text { Understanding }\end{array}$ & $\begin{array}{ll}+ & \text { BPM should create shared meaning. } \\
\text { - } & \text { It should not be the language of experts. }\end{array}$ \\
\hline 8. & Principle of Purpose & $\begin{array}{ll}+ & \text { BPM should contribute to strategic value creation. } \\
- & \text { It should not be done for the sake of doing it. }\end{array}$ \\
\hline 9. & Principle of Simplicity & $\begin{array}{ll}+ & \text { BPM should be economical. } \\
- & \text { It should not be over-engineered. }\end{array}$ \\
\hline 10. & $\begin{array}{l}\text { Principle of Technology } \\
\text { Appropriation }\end{array}$ & $\begin{array}{ll}+ & \text { BPM should make opportune use of technology. } \\
\text { - } & \text { It should not consider technology management as an } \\
\text { after-thought. }\end{array}$ \\
\hline
\end{tabular}

Table 1. Ten principles of good BPM

\subsection{Principle of Context Awareness}

Many BPM projects apply one and the same cookbook approach to all organizational processes, which results in numerous project failures. Going beyond this narrow approach, the principle of context-awareness points out that BPM requires consideration of the given organizational setting. Context awareness involves a concern for factors that distinguish BPM contexts between organizations, such as size, strategy, industry, market, and objectives of BPM, and within organizations, such as types of processes or available resources. For example, small companies may have less personnel resources for BPM governance than large companies, while specific IT systems may not yield efficiency gains in all processes to the same extent.

The principle of context awareness is rooted in contingency theory (Donaldson, 2001). According to this theory, organizational effectiveness is based on the fit between 
organizational characteristics and contingencies, i.e. context factors. Therefore, the best way to manage is context specific, which requires organizations to adapt to their given contingencies. Accordingly, the principle of context awareness assumes that there is no unique way of managing business processes. While our understanding of this principle refers to the context-aware implementation of BPM (resp. management of processes), extant BPM research has explored the adaptation of processes to their given context, most notably in the areas of modeling context-aware processes (Ploesser and Recker, 2011; Rosemann et al., 2008) or context-aware process mining (Günther et al., 2008).

In practice, most BPM programs still follow a one-size-fits-all approach that does not distinguish between external or internal contingencies, and may thus lead to major setbacks regarding the internal support for BPM in the organization. Difficulties that arise based on such an approach and the related disappointments are likely to have a negative influence on the perception of BPM. Therefore, BPM should be adapted to suit the existing circumstances. It should fit the organization and, in particular, differentiate the management of business processes according to the process nature, e.g. degree of automation, standardization, repetitiveness etc.

\subsection{Principle of Continuity}

BPM is often introduced in an organization through short-term projects that aim to solve specific inefficiencies. Yet, it is important to go beyond only achieving quick wins. The principle of continuity stresses that BPM should be a permanent practice that facilitates continuous gains in efficiency and effectiveness. Establishing a long-term BPM approach and installing a process mindset sustainably is important in order to be able to leverage the potential and the value of BPM.

While research found that BPM only leads to sustained competitive advantage if business process are continuously improved (Trkman, 2010; Hammer, 2010), literature also emphasized the benefits of radical redesign of organizations in one big bang (Hammer and Champy, 1993). Acknowledging that such a huge overhaul is necessary at certain points in time, researchers today agree that BPM goes beyond these single interventions. Today it is well established that any isolated project - incremental or radical in scope - may lead to certain gains, but it can at best create a temporary optimum that will soon lose ground, as the economic environment and competition continue to evolve (Hammer, 2010). 
In order for BPM not to be a one-off change project, it is important to establish a process mindset (vom Brocke et al., 2010a). This can be done by creating and maintaining an organizational culture that is supportive of BPM (Schmiedel et al., 2013). If BPM-facilitating values become part of the organizational culture, BPM will be a natural part of daily work. The internalization of these values can be stimulated by adapting communication, leadership behaviors, reward structures and governance practices.

\subsection{Principle of Enablement}

Many organizations merely invest in BPM tools or consultants rather than in capabilities. Thus, they are likely to acquire components that they may not really understand and may not be capable of fully utilizing to achieve their process objectives. The principle of enablement focuses on the need to develop individual and organizational BPM capabilities.

Extant research found that a broad range of personal competencies of key BPM employees play a crucial role in actively developing organizational BPM capabilities (Müller et al., 2013). Further, research examined how to assess which BPM capabilities are needed at which stage and how to develop them (Plattfaut et al., 2011). Studies found that such questions should be answered taking the maturity of the company into consideration (Škrinjar and Trkman, 2013). In this regard, maturity models (Rosemann et al., 2006) offer a strong possibility for identifying and evaluating required BPM capabilities.

Organizations which develop BPM capabilities, for example through considering BPM competencies in staffing key BPM positions (Müller et al., 2013), prevent BPM from being limited to firefighting, such as through the adoption of ad-hoc solutions from external consultants. In fact, BPM should not only focus on building capabilities currently needed by an organization but also on building dynamic capabilities needed for responding effectively to future contingencies (Teece, 2009; Pavlou and El Sawy, 2011).

\subsection{Principle of Holism}

BPM projects often only focus on single organizational aspects, such as the operational excellence of a single process, a single department, or for support processes only. Resulting disappointments on the limited contribution of such projects call for the principle of holism, which emphasizes the need for a holistic scope of BPM. Two dimensions can be distinguished: first, BPM should not have an isolated focus on specific areas of an organization, i.e. BPM should not be a project only in one or few departments but run throughout the value chain. Second, BPM should not have an isolated focus on specific 
aspects, i.e. BPM should not be solely conceived as a modeling exercise only but as a holistic approach that comprises, for example, strategic, methodological, technical, and social aspects. While the origins of BPM research focused on IT systems for process support and process modeling (Jeston and Nelis, 2008), academics have, in recent years, become aware that BPM requires a holistic understanding (Hammer, 2010; Harmon, 2010). Today, there is growing consensus on factors to be considered in BPM (vom Brocke and Rosemann, 2013). For example, the maturity model developed by de Bruin and Rosemann (2005) includes the factors strategic alignment, governance, methods, IT, people, and culture. Other researchers also called for the inclusion of such factors in a holistic BPM approach (Hammer, 2007; Trkman, 2010; Willaert et al., 2007).

Still, starting with a more narrow/functional focus rather than with an enterprise-wide focus can increase the initial BPM performance (Altinkemer et al., 2011). Nevertheless, even such BPM initiatives need to consider the enterprise environment and the current and future implications of the project. For instance, the choice of IT systems should not merely meet the local requirements of one function but, rather, fit the organization. Organizations should, thus, define an inclusive scope of BPM, integrating recognized BPM factors across the entire company.

\subsection{Principle of Institutionalization}

In many organizations, entrenched habits and adverse circumstances promote silo behavior, preventing horizontal process thinking and acting. The principle of institutionalization calls for embedding BPM in the organizational structure. The introduction of formal BPM roles and responsibilities ensures that the "horizontal discipline" is given its due weight and that the organization is rebalanced in favor of a more customer-centric, horizontal integration of work. Researchers generally use the notion of business process governance to refer to the need to institutionalize this horizontal thinking (Markus and Jacobson, 2010). The literature has intensively discussed the trade-offs in finding the right balance between using institutional or impersonal governance mechanisms (e.g. rules, formal roles and accountability structures) and personal governance mechanisms (i.e. administered by individuals who may or may not have formally designated accountability) to direct, coordinate and control process work endto-end (Galbraith, 1994).

To prevent BPM from being only an ad-hoc responsibility, the role of process owners with real responsibility, accountability and authority is pivotal (Power, 2011). Also, many 
organizations have found that a centralized BPM support organization (e.g. BPM Centre for Excellence or BPM Office) can help raise the general level of process orientation (Rosemann, 2010). These support organizations typically use multi-dimensional BPM maturity assessments to guide the journey towards becoming more process-oriented, however their portfolio of service offerings may vary widely (Rosemann, 2010; Willaert et al., 2007).

\subsection{Principle of Involvement}

Organizational changes can be very threatening and often trigger employee resistance. The principle of involvement stresses that all stakeholder groups who are affected by BPM should be involved. Since introducing BPM typically means that many jobs change and many people will be affected, the responsiveness of people and their true commitment toward the change is critical to the success of BPM. The active involvement of employees fosters a true sense of ownership and even increases organizational performance.

Studies found that organizations often attempt to limit stakeholder involvement by simply gathering information through interviews and then having processes (re-) designed by a dedicated team of experts (Rosemann, 2006b; Sarker and Sidorova, 2006). The (re-) design process, however, is likely to be more important than the final design. Ideally, the design process is a collaborative effort by group of actively involved stakeholders that represent the voice of their peers and that act as “change agents” (Rosemann, 2006a). The broader group of all stakeholders can be involved through mechanisms such as interactive feedback sessions, idea boxes and collaborative process modeling.

In conclusion, BPM practice should not neglect the impact of employee participation. While the active involvement of stakeholders can be costly, and the required effort can trigger resistance, creating a sense of involvement will pay off in commitment, ownership, and diminished levels of resistance. It will also create a feeling of being part of a bigger picture, helping to make BPM “the way we do things around here”.

\subsection{Principle of Joint Understanding}

Many BPM projects split employees in that only few understand the process language that is used. The principle of joint understanding draws attention to BPM as a mechanism to introduce and sustain a common language allowing different stakeholders to view, frame and analyze organizational systems. The embodiment of process thinking into an organizational culture requires that 'process' is a term that is actively shared by all stakeholders. Ideally, 
processes are part of all conversations, reflecting a shared understanding of processes and ways in which their improvement can be sought.

In BPM terms, most attempts at creating joint understanding revolve around the use of process models (Curtis et al., 1992). Typically, process modeling is performed with a view towards using a common, often graphical language to describe, communicate and analyze processes. Research has shown that it encourages users to conceptualize processes in terms of events, tasks, actors and other notions (Recker et al., 2009). However, process models should not remain complex artifacts that can only be comprehended by experts (Mendling et al., 2012), but instead should aspire to be simple and intuitive.

This way, organizations can create shared meaning and a common understanding across all stakeholders involved in business processes, independent of their expertise in process modeling languages. Fortunately, several guidelines have been researched (Mendling et al., 2010; La Rosa et al., 2011a; La Rosa et al., 2011b; Becker et al., 2000) that can help organizations to use process modeling in simple, understandable ways to create shared meaning - through reduction of complexity (Recker, 2013), coloring (Reijers et al., 2011a), labeling (Mendling et al., 2010), modularization (Reijers et al., 2011b) and other mechanisms. Still, often the question remains whether advanced and sophisticated process models using advanced formalism are truly the language that the organization wants to speak to communicate about their processes -research shows that novices, for instance, prefer talking in terms of storyboards or even cartoons (Recker et al., 2012b).

\subsection{Principle of Purpose}

Following a BPM approach because it seems to be in vogue is likely to lead to project failures. The principle of purpose highlights the role of BPM as a management method to achieve organizational change and create value. It indicates the requirement of BPM to align with a strategic mission and goals. While this principle is seemingly obvious, it is in practice often forgotten. It is particularly important as it focuses on the ability of BPM to create transparency about the business and the organizational system. Perusing this transparency then helps to create and improve the value that can be generated within the organization. In research, the principle of purpose is often equated with the notion of value-oriented BPM (Franz and Kirchmer, 2012; vom Brocke et al., 2010b). It highlights that value creation can be achieved by different mechanisms proffered by BPM and that the choice of mechanism should be made in alignment with a strategic purpose, e.g. efficiency gains, compliance 
enforcement, networking with business partners, or integration and agility. Case studies demonstrate that the purpose of BPM can be manifold and that BPM has the potential to serve many purposes (Bandara et al., 2010b), including green initiatives and sustainability transformations (vom Brocke et al., 2012).

In practice, a common pitfall of BPM activities is overdoing some of the tasks (e.g. process modeling) and forgetting the true purpose of the activity (e.g. creating a shared understanding that allows process improvement opportunities to be revealed). Then BPM becomes l'Art pour l'Art (Rosemann, 2006b): a self-absorbing exercise gaining and feeding off its own momentum without fulfilling a larger and wider purpose. Failure to achieve a valuable purpose, however, can lead to dissatisfaction - and eventually even discontinuance of BPM (Nwabueze, 2012; Karim and Arif-Uz-Zaman, 2013).

\subsection{Principle of Simplicity}

BPM initiatives can easily be set up consuming enormous amounts of resources. The principle of simplicity suggests that the amount of resources (e.g. effort, time, money) invested into BPM should be economical. Focusing on simple solutions means balancing the inputs against the output of more efficient and effective organizational processes. An organization should carefully choose which processes require which level of attention from a strategic, technical, staffing, etc. viewpoint.

As a research domain, BPM has evolved into a complex array of methodologies and practices both from an IT and a business perspective without numerous guidelines on when and how to best implement which of these (Rohloff, 2009). In addition to the multiple techniques encompassed in BPM, its outcomes can be used for a variety of purposes such as for the documentation and the improvement of business processes, for their compliance (with e.g. Sarbanes-Oxley and Basel II), or for software selection, configuration and development (Rosemann, 2006a).

Since these developments add to the inherent complexity of managing business processes, organizations should not develop a habit of over-engineering. In case of uncertainties about which options to follow, the paraphrase of Occam's razor can be helpful: one should not increase, beyond what is necessary, the number and intensity of BPM-related projects and activities required to realize efficient and effective business processes. Every company should look for the simplest way to achieve its BPM-related goals. 


\subsection{Principle of Technology Appropriation}

Countless IT solutions can be used to foster the efficiency and effectiveness of business processes. The principle of technology appropriation emphasizes that BPM should make opportune use of technology, particularly IT. For example, process re-engineering projects have benefited tremendously from the introduction of enterprise systems. Continuous improvement has gone mainstream thanks to the introduction of business intelligence solutions. Today, predictions abound on the transformative power of new IT, like cloud, mobile, social, big data and analytics technologies.

In research, the role of the IT resource in driving the progression of value creation with BPM is well established (Davenport, 1993; van den Bergh and Viane, 2012; Mitchell and Zmud, 1999). Yet, serious issues with aligning business and IT management have existed for over 30 years (Luftman and Derksen, 2012). Despite these issues, research suggests that best-in-class CIOs have realized that business and IT need to find better ways to realize enterprise value together, rather than locally optimized solutions or functional value (Viaene et al., 2011). While modern organizations are found to manage end-to-end processes rather than IT per se, treating IT management as an after-thought when introducing IT into work environments may seriously jeopardize the continuity, the growth, and the transformational capability of an enterprise as a whole. The selection, adoption and exploitation of IT should be inherent in BPM and managed from the point of view of supporting the enterprise, rather than single departments or individuals. Fortunately, there are already organizations managing IT outside of the business-IT duality.

\section{Discussion}

The principles of good BPM are partially reflected in the state of the art research on how to adopt BPM in practice. Based on our experience, we now introduce some fundamental implications both for research and practice that are related to the principles. Further, we point out some limitations and potential ways to overcome these in future research.

\subsection{Informing BPM Practice through the Ten Principles}

For practice, the ten principles provide normative statements on how to scope and implement BPM as well as normative advice on what not to do. The condensed form of the statements helps to better master the huge knowledge base on BPM available today. Managers can also use the principles as a checklist in order to assure the appropriateness of their own BPM 
approach. Thus, the principles serve both to coordinate internal initiatives as well as to evaluate the offering of third parties, such as consultancy companies. As to the latter, the principles can certainly help to further develop service offerings. That is, businesses can use the principles to shape service offerings contributing to a wider service portfolio necessary for BPM in an organization. Table 2 provides an overview of sample questions regarding each of the principles that are aimed at guiding BPM practice.

\begin{tabular}{|c|c|c|}
\hline No. & Principle & Questions to guide BPM practice \\
\hline 1. & $\begin{array}{l}\text { Principle of } \\
\text { Context- } \\
\text { Awareness }\end{array}$ & $\begin{array}{l}\text { - In what context is our BPM initiative set up? } \\
\text { - What factors characterize the context of application? } \\
\text { - What requirements can we derive from this context for the BPM } \\
\text { initiative? }\end{array}$ \\
\hline 2. & $\begin{array}{l}\text { Principle of } \\
\text { Continuity }\end{array}$ & $\begin{array}{l}\text { - How do we sustain a BPM initiative? } \\
\text { - How do we establish continuous improvement and innovation of } \\
\text { business processes in the long run? } \\
\text { - What is the overall agenda connecting different BPM projects? }\end{array}$ \\
\hline 3. & $\begin{array}{l}\text { Principle of } \\
\text { Enablement }\end{array}$ & $\begin{array}{l}\text { - What measures have we taken to develop capabilities in BPM? } \\
\text { - Do we know what capabilities are needed in different areas of the } \\
\text { organization? } \\
\text { - How do we establish the required dynamic capabilities for BPM } \\
\text { success? }\end{array}$ \\
\hline 4. & $\begin{array}{l}\text { Principle of } \\
\text { Holism }\end{array}$ & $\begin{array}{l}\text { - To what other business or management areas does our initiative } \\
\text { relate? } \\
\text { - Which of these areas need to be taken into account? } \\
\text { - What synergies can we leverage? }\end{array}$ \\
\hline 5. & $\begin{array}{l}\text { Principle of } \\
\text { Institutional- } \\
\text { ization }\end{array}$ & $\begin{array}{l}\text { - Who takes ownership of BPM? } \\
\text { - Which organizational structure supports BPM? } \\
\text { - What are the incentives for our employees to engage in BPM? }\end{array}$ \\
\hline 6. & $\begin{array}{l}\text { Principle of } \\
\text { Involvement }\end{array}$ & $\begin{array}{l}\text { - Which stakeholders are affected by a our BPM initiative? } \\
\text { - What are the specific preferences of these stakeholders? } \\
\text { - How can their perspectives be considered to increase support? }\end{array}$ \\
\hline 7. & $\begin{array}{l}\text { Principle of } \\
\text { Joint } \\
\text { Understanding }\end{array}$ & $\begin{array}{l}\text { - What is a language all employees would understand? } \\
\text { - What are essential concepts relevant in different business areas? } \\
\text { - How can language gaps between different groups be bridged? }\end{array}$ \\
\hline 8. & $\begin{array}{l}\text { Principle of } \\
\text { Purpose }\end{array}$ & $\begin{array}{l}\text { - What do we want to achieve with BPM? } \\
\text { - What alternatives do we have? } \\
\text { - How can we measure the gains of BPM? }\end{array}$ \\
\hline 9. & $\begin{array}{l}\text { Principle of } \\
\text { Simplicity }\end{array}$ & $\begin{array}{l}\text { - Which BPM activities should we focus on? } \\
\text { - How can we reduce effort in BPM? } \\
\text { - What would happen if we stop supporting certain BPM activities? }\end{array}$ \\
\hline 10. & \begin{tabular}{l|} 
Principle of \\
Technology \\
Appropriation
\end{tabular} & $\begin{array}{l}\text { - Which technology is available to support a particular BPM purpose? } \\
\text { - How can we make sure the technology gets used in this specific } \\
\text { context? }\end{array}$ \\
\hline
\end{tabular}




\begin{tabular}{|c|c|c|}
\hline & $\begin{array}{l}\text { - How can we manage the organizational transformation that comes } \\
\text { with the use of a new technology? }\end{array}$ \\
\hline
\end{tabular}

Table 2. $\quad$ Sample questions to guide BPM practice

\subsection{A Research Agenda based on the Ten Principles}

For research, the principles effect a reflection on past and current BPM research and also describe a roadmap with important areas requiring future research contributions. The principles of context awareness and the principle of purpose, for instance, illustrate that BPM needs to be sensitive to a wide range of both business contexts and strategic orientations. The related research challenge is thus to examine how existing methods and tools need to be chosen, extended or revised to incorporate the extended scope and application areas - be it to be able to visualize relevant information for novel purposes such as the potential for sustainability improvement in a process model (Recker et al., 2012a) or to examine how process performance management can be applied successfully given contextual or strategic contingencies (Blasini and Leist, 2013).

Principles such as enablement, institutionalization, involvement, and joint understanding, on the other hand, emphasize the role of people in making BPM initiatives effective. These are areas which have been widely neglected in previous research, and that need to be addressed in much more detail and more expansively in the future. We provide a roadmap for future research by identifying relevant research questions for each principle in Table 3.

\begin{tabular}{|l|l|l|}
\hline No. & Principle & Questions to guide BPM research \\
\hline 1. & $\begin{array}{l}\text { Principle of } \\
\text { Context- } \\
\text { Awareness }\end{array}$ & $\begin{array}{l}\text { - Which typical context factors determine BPM approaches? } \\
\text { - Which BPM approaches are effective in specific contexts? }\end{array}$ \\
\hline 2. & $\begin{array}{l}\text { Principle of } \\
\text { Continuity }\end{array}$ & $\begin{array}{l}\text { - How can the progress of the BPM program be measured? } \\
\text { - How can BPM be realized as part of the organizational culture? }\end{array}$ \\
\hline 3. & $\begin{array}{l}\text { Principle of } \\
\text { Enablement }\end{array}$ & $\begin{array}{l}\text { - What specific organizational capabilities are required to realize BPM? } \\
\text { - How can these best be implemented? }\end{array}$ \\
\hline 4. & $\begin{array}{l}\text { Principle of } \\
\text { Holism }\end{array}$ & $\begin{array}{l}\text { - Which factors are necessary and which are sufficient for BPM } \\
\text { success? }\end{array}$ \\
\hline 5. & $\begin{array}{l}\text { Principle of } \\
\text { Institutional- } \\
\text { ization }\end{array}$ & $\begin{array}{l}\text { - What are measurement criteria for these factors? } \\
\text { - What type of key performance indicators support BPM best? }\end{array}$ \\
\hline
\end{tabular}




\begin{tabular}{|c|c|c|}
\hline 6. & $\begin{array}{l}\text { Principle of } \\
\text { Involvement }\end{array}$ & $\begin{array}{l}\text { - Does active involvement in process model creation change the use of } \\
\text { process models? } \\
\text { - What is the return on investment of involving vs. informing key } \\
\text { stakeholders? }\end{array}$ \\
\hline 7. & $\begin{array}{l}\text { Principle of } \\
\text { Joint } \\
\text { Understanding }\end{array}$ & $\begin{array}{l}\text { - Are process models a good mechanism to create joint understanding } \\
\text { between business and IT? } \\
\text { - Which elements of processes need to be understood? }\end{array}$ \\
\hline 8. & $\begin{array}{l}\text { Principle of } \\
\text { Purpose }\end{array}$ & $\begin{array}{l}\text { - What are configuration mechanisms to tailor BPM depending on } \\
\text { purpose? } \\
\text { - For which purposes should BPM not be applied? }\end{array}$ \\
\hline 9. & $\begin{array}{l}\text { Principle of } \\
\text { Simplicity }\end{array}$ & $\begin{array}{l}\text { - What are BPM failure factors? } \\
\text { - What is the tipping point for effort invested in BPM? } \\
\text { - Which BPM activities contribute most to value-creation? }\end{array}$ \\
\hline 10. & $\begin{array}{l}\text { Principle of } \\
\text { Technology } \\
\text { Appropriation }\end{array}$ & $\begin{array}{l}\text { - What are criteria to identify the appropriate BPM technology for a } \\
\text { particular purpose? } \\
\text { - What is the value of using a certain BPM technology vs. another? }\end{array}$ \\
\hline
\end{tabular}

Table 3. Questions to guide BPM research

\subsection{Limitations}

Both the scope and the realization of our paper are limited in a number of ways. First, our paper presents a viewpoint that is informed by focus groups with academics and practitioners. As such, this work should not be seen as final. Instead, we invite practitioners and academics alike to apply, challenge and extend our viewpoint on BPM as a research domain. With our ten principles of good BPM, we aim to provide a starting point to generate a joint understanding of the BPM field.

Second, the ten principles may seem generic in the sense that they might also hold true for the management of projects in general. They were, however, specifically derived for BPM: we asked BPM experts for principles of good BPM. Also, we elaborate on each of the principles from a dedicated BPM perspective. Nonetheless, we do acknowledge that some of the identified principles might also apply to other management areas and wish to highlight that this reflects our understanding of BPM as a management capability. Therefore, we recommend that future research look into the applicability of the ten principles to other management areas.

Third, the tight relation between the principles leads to certain overlaps in their meaning for the BPM domain. Nevertheless, each of the principles is, at its core, distinct from the others. For example, the principle of continuity states that BPM should be a permanent practice. One way to realize continuity may be to embed BPM in the organizational structure (principle of 
institutionalization). While the two principles are closely related, their cores are distinct as one emphasizes time (continuity) whereas the other emphasizes structure (institutionalization). Similarly, each of the other principles draws attention to a specific and distinct aspect of good BPM.

Finally, some principles might, at first sight, seem contradictory, like the principle of holism and the principle of simplicity. Yet, a closer look shows that these principles are rather complementary than contradictory. While the principle of holism calls for inclusiveness in scope, the principle of simplicity recommends an economic way for such inclusiveness. In other words, while BPM should not have an isolated focus, it does not mean all areas in the organization need to necessarily receive the same level of attention from a strategic, technical, cultural, etc. perspective. Nevertheless, future research should further examine the relations between the identified principles.

\section{Conclusions}

In this viewpoint paper we have shared our view of ten principles for good BPM. We consider these principles a starting point for an important discussion on further shaping the BPM domain both in academia and practice. The foremost intention is to foster a joint understanding of what BPM actually requires in order to be applied successfully, i.e. an understanding of what characterizes BPM as a research domain and what guides its successful use in organizational practice. We do not wish to argue that every single contribution needs to cover the entire scope of the ten principles, but every initiative needs to consider its specific contribution within the overall field of BPM. Our aim was to provide a starting point for such a discussion in the BPM research community. In fact, the ten principles offer a framework to conceptualize both current and future research in a critical way. For example, further analyses may examine how much research has been conducted on which of the ten principles over the past ten years, how far research strikes a balance in developing understanding on the positive and the negative manifestations of the principles, and which principles are over-, which are under-studied.

In deciding in which ways we can best act upon the principles of good BPM, knowledge about the principles also must be considered in the shapes and formats of BPM teaching and education. We need to update our curriculum according to recent developments in BPM. Bergener et al. (2012), for instance, have analyzed BPM curricula and found that courses still focus on methodological skills, in particular process modeling. Similar studies over recent years echoed this sentiment and lament singular focus areas in BPM education (Bandara et 
al., 2010a). In light of the ten principles, it remains to be asked whether our teaching provides a comprehensive understanding of good BPM, or whether we only teach within our own comfort zone of knowledge created through research. In more pointed terms, our principles suggest that we need to stop teaching BPMN and labeling it BPM. It may well be important to continue with the teaching of BPMN (Recker and Rosemann, 2009); however, within the scope of teaching a "modeling notation" rather than BPM as such.

We elaborated on each principle and offered normative advice for their implementation in BPM practice as well as suggestions for a roadmap for future BPM research. Yet, we do not claim that our set of principles is complete. The list of ten principles is our interpretation of several extremely important principles. In fact, we ask fellow researchers to challenge and extend our view of these principles - we would indeed see this as a fruitful development of the BPM research area to commonly transcend current boundaries in terms of richness and reach. To this end, we have set up a website that provides interested BPM fellows the opportunity to freely and openly contribute to the discussion and formation of the principles (www.bpm-principles.org) and, ultimately, to progress in the field of BPM.

\section{References}

ABPM, A.o.B.P.M.P. (2009), Guide to the business process management common body of knowledge, CreateSpace Independent Publishing Platform.

Altinkemer, K., Ozcelik, Y. and Ozdemir, Z. (2011), "Productivity and performance effects of business process reengineering: A firm-level analysis", Journal of Management Information Systems, Vol. 27, No. 4, pp. 129-161.

Ariyachandra, T.R. and Frolick, M.N. (2008), "Critical success factors in business performance management: Striving for success", Information Systems Management, Vol. 25, No. 2, pp. 113-120.

Armistead, C. (1996), "Principles of business process management", Managing Service Quality, Vol. 6, No. 6, pp. 48-52.

Bai, C. and Sarkis, J. (2013), "Model for evaluating business process management critical success factors", International Journal of Production Economics, Vol. 146, No. 1, pp. 281-292.

Bandara, W., Chand, D.R., Chircu, A.M., Hintringer, S., Karagiannis, D., Recker, J., van Rensburg, A., Usoff, C. and Welke, R.J. (2010a), "Business Process Management Education in Academia: Status, Challenges, and Recommendations", Communications of the Association for Information Systems, Vol. 27, No. 41, pp. 743-776.

Bandara, W., Gable, G. and Rosemann, M. (2005), "Factors and measures of business process modeling: Model building through a multiple case study", European Journal of Information Systems, Vol. 14, No. 4, pp. 347-360.

Bandara, W., Guillemain, A. and Coogans, P. (2010b), "Prioritizing Process Improvement: An Example from the Australian Financial Services Sector", in vom Brocke, J. and Rosemann, M. (Eds.), Handbook on Business Process Management 2: Strategic Alignment, Governance, People and Culture, Springer, Berlin, Germany, pp. 177-195. 
Becker, J., Rosemann, M. and Uthmann, C. (2000), "Guidelines of business process modeling", Business Process Management, Springer, Berlin / Heidelberg, pp. 30-49.

Bergener, K., vom Brocke, J., Hofmann, S., Stein, A. and vom Brocke, C. (2012), "On the importance of agile communication skills in BPM education: Design principles for international seminars", Knowledge Management \& E-Learning: An International Journal, Vol. 4, No. 4, pp. 415-434.

Blasini, J. and Leist, S. (2013), "Success Factors in Process Performance Management", Business Process Management Journal, Vol. 19, No. 3, pp. 477-495.

Boynton, A.C. and Zmud, R.W. (1984), "An assessment of critical success factors", Sloan Management Review, Vol. 25, No. 4, pp. 17-27.

Burlton, R. (2001). "Principles of process management", available at: http://www.informit.com/articles/article.aspx?p=131055\&seqNum=3 (accessed 12 September 2013).

Burlton, R. (2012). "Business process manifesto", BPTrends, available at: http://www.bptrends.com/bpmmanifesto.cfm (accessed 25 March 2013).

Chircu, A.M., Grover, V., Majchrzak, A. and Rosemann, M. (2010), "Business process management and the IS field: Have we finally arrived or just missed the boat?", 31st International Conference on Information Systems (ICIS 2010), Saint Louis, Missouri.

Curtis, B., Kellner, M.I. and Over, J. (1992), "Process Modeling", Communications of the ACM, Vol. 35, No. 9, pp. 75-90.

Davenport, T. (1993), Process innovation: Reengineering work through information technology, Harvard Business Press, Boston.

Donaldson, L. (2001), The contingency theory of organizations, Sage Publications, Thousand Oaks, London, New Delhi.

Franz, P. and Kirchmer, M. (2012), Value-Driven Business Process Management: The ValueSwitch for Lasting Competitive Advantage, McGraw-Hill, New York.

Galbraith, J.R. (1994), Competing with flexible lateral organizations, Addison-Wesley, Massachusetts.

Günther, C., Rinderle-Ma, S., Reichert, M., Van der Aalst, W.M.P. and Recker, J. (2008), "Using Process Mining to Learn From Process Changes in Evolutionary Systems", International Journal of Business Process Integration and Management, Vol. 3, No. 1, pp. 61-78.

Hammer, M. (2007), "The process audit", Harvard Business Review, Vol. 85, No. 4, pp. 111123.

Hammer, M. (2010), "What is business process management?", in vom Brocke, J. and Rosemann, M. (Eds.), Handbook on business process management: Introduction, methods and information systems, Springer, Berlin / Heidelberg, pp. 3-16.

Hammer, M. and Champy, J.A. (1993), Reengineering the corporation: A Manifesto for Business Revolution, Harper Business Books, New York.

Harmon, P. (2010), "The scope and evolution of business process management", in vom Brocke, J. and Rosemann, M. (Eds.), Handbook on business process management. Introduction, methods and information systems, Springer, Berlin, pp. 37-81.

Hevner, A.R., March, S.T., Park, J. and Ram, S. (2004), "Design science in information systems research", Management Information Systems Quarterly, Vol. 28, No. 1, pp. 75-105.

Jeston, J. and Nelis, J. (2008), Business process management. Practical guidelines to successful implementations, Elsevier, Oxford.

Karim, A. and Arif-Uz-Zaman, K. (2013), "A methodology for effective implementation of lean strategies and its performance evaluation in manufacturing organizations", Business Process Management Journal, Vol. 19, No. 1, pp. 169-196. 
Karim, J., Somers, T.M. and Bhattacherjee, A. (2007), "The impact of ERP implementation on business process outcomes: A factor-based study", Journal of Management Information Systems, Vol. 24, No. 1, pp. 101-134.

King, S.F. and Burgess, T.F. (2006), "Beyond critical success factors: A dynamic model of enterprise system innovation", International Journal of Information Management, Vol. 26, No. 1, pp. 59-69.

Klein, H.K. and Myers, M.D. (1999), "A set of principles for conducting and evaluating interpretive field studies in information systems", Management Information Systems Quarterly, Vol. 23, No. 1, pp. 67-94.

La Rosa, M., Ter Hofstede, A.H.M., Wohed, P., Reijers, H.A. and van der Aalst, W.M.P. (2011a), "Managing process model complexity via concrete syntax modifications", IEEE Transactions on Industrial Informatics, Vol. 7, No. 2, pp. 255-265.

La Rosa, M., Wohed, P., Mendling, J., Ter Hofstede, A.H.M., Reijers, H.A. and Van der Aalst, W.M.P. (2011b), "Managing process model complexity via abstract syntax modifications ", IEEE Transactions on Industrial Informatics, Vol. 7, No. 4, pp. 614629.

Luftman, J. and Derksen, B. (2012), "Key issues for IT executives 2012: Doing more with less", MIS Quarterly Executive, Vol. 11, No. 4.

Markus, M.L. and Jacobson, D.D. (2010), "Business process governance", in vom Brocke, J. and Rosemann, M. (Eds.), Handbook on business process management: Strategic alignment, governance, people and culture, Springer, Berlin / Heidelberg, pp. 201222.

Mendling, J., Reijers, H.A. and Van der Aalst, W.M.P. (2010), "Seven process modeling guidelines (7PMG)", Information and Software Technology Vol. 52, No. 2, pp. 127136.

Mendling, J., Strembeck, M. and Recker, J. (2012), "Factors of process model comprehension: Findings from a series of experiments", Decision Support Systems, Vol. 53, No. 1, pp. 195-206.

Mitchell, V.L. and Zmud, R.W. (1999), "The effects of coupling IT and work process strategies in redesign projects", Organization Science, Vol. 10, No. 4, pp. 424-438.

Müller, O., Schmiedel, T., Gorbacheva, E. and vom Brocke, J. (2013), "Toward a typology of business process management professionals: Identifying patterns of competences through latent semantic analysis", manuscript.

Nwabueze, U. (2012), "Process improvement: The case of a drugs manufacturing company", Business Process Management Journal, Vol. 18, No. 4, pp. 576-584.

Pavlou, P.A. and El Sawy, O.A. (2011), "Understanding the elusive black box of dynamic capabilities", Decision Sciences, Vol. 42, No. 1, pp. 239-273.

Plattfaut, R., Niehaves, B., Pöppelbuß, J. and Becker, J. (2011), "Development of BPM capabilities: Is maturity the right path?", 19th European Conference on Information Systems (ECIS 2011), Aalto, Finland.

Ploesser, K. and Recker, J. (2011), "Context-Aware Methods for Process Modeling ", in Beckmann, J.A. (Ed.) Business Process Modeling: Software Engineering, Analysis and Applications, Nova Publishers, Hauppauge, New York.

Power, B. (2011), "Where have all the process owners gone", HBR Blog Network, No. January 7.

Recker, J. (2013), "Empirical investigation of the usefulness of gateway constructs in process models", European Journal of Information Systems, Vol. 22, No. 6, pp. 673-689.

Recker, J. and Rosemann, M. (2009), "Teaching Business Process Modeling - Experiences and Recommendations", Communications of the Association for Information Systems, Vol. 25, No. 32, pp. 379-394. 
Recker, J., Rosemann, M., Indulska, M. and Green, P. (2009), "Business process modeling: A comparative analysis", Journal of the Association for Information Systems, Vol. 10, No. 4, pp. 333-363.

Recker, J., Rosemann, M., Roohi Goohar, E., Hjalmarsson, A. and Lind, M. (2012a), "Modeling and Analyzing the Carbon Footprint of Business Processes", in vom Brocke, J., Seidel, S. and Recker, J. (Eds.), Green Business Process Management Towards the Sustainable Enterprise, Springer, Heidelberg, Germany, pp. 93-110.

Recker, J., Safrudin, N. and Rosemann, M. (2012b), "How Novices Design Business Processes", Information Systems, Vol. 37, No. 6, pp. 557-573.

Reijers, H.A., Freytag, T., Mendling, J. and Eckleder, A. (2011a), "Syntax highlighting in business process models", Decision Support Systems, Vol. 51, No. 3, pp. 339-349.

Reijers, H.A., Mendling, J. and Dijkman, R.M. (2011b), "Human and automatic modularizations of process models to enhance their comprehension", Information Systems, Vol. 36, No. 5, pp. 881-879.

Rohloff, M. (2009), "Case study and maturity model for business process management implementation", 7th International Conference on Business Process Management, Ulm, Germany.

Rosemann, M. (2006a), "Potential pitfalls of process modeling: part A", Business Process Management Journal, Vol. 12, No. 2, pp. 249-254.

Rosemann, M. (2006b), "Potential pitfalls of process modeling: part B", Business Process Management Journal, Vol. 12, No. 3, pp. 377-384.

Rosemann, M. (2010), "The service portfolio of a BPM center of excellence", in vom Brocke, J. and Rosemann, M. (Eds.), Handbook on business process management: Strategic alignment, governance, people and culture, Springer, Berlin / Heidelberg, pp. 267284.

Rosemann, M. and de Bruin, T. (2005), "Towards a business process management maturity model", 13th European Conference on Information Systems (ECIS 2005), Regensburg, Germany.

Rosemann, M., de Bruin, T. and Power, B. (2006), "BPM Maturity", in Jeston, J. and Nelis, J. (Eds.), Business Process Management: Practical Guidelines to Successful Implementations, 3rd ed, Butterworth-Heinemann, Oxford, England, pp. 299-315.

Rosemann, M., Recker, J. and Flender, C. (2008), "Contextualization of Business Processes", International Journal of Business Process Integration and Management, Vol. 3, No. 1, pp. 47-60.

Rosemann, M. and vom Brocke, J. (2010), "The six core elements of business process management", in vom Brocke, J. and Rosemann, M. (Eds.), Handbook on business process management. Introduction, methods and information systems, Springer, Berlin, pp. 109-124.

Sarker, S. and Sidorova, A. (2006), "Understanding business process change failure: An actor-network perspective", Journal of Management Information Systems, Vol. 23, No. 1, pp. 51-86.

Schmiedel, T., vom Brocke, J. and Recker, J. (2013), "Which Cultural Values Matter to Business Process Management? Results from a Global Delphi Study", Business Process Management Journal, Vol. 19, No. 52, pp. 292-317.

Škrinjar, R. and Trkman, P. (2013), "Increasing process orientation with business process management: critical practices", International Journal of Information Management, Vol. 33, No. 1, pp. 48-60.

Teece, D.J. (2009), Dynamic capabilities and strategic management: Organizing for innovation and growth, Oxford University Press, Oxford, New York.

Trkman, M. and Trkman, P. (2009), "A wiki as internet: A critical analysis using the Delone \& McLean Model", Online Information Review, Vol. 33, No. 6, pp. 1087-1102. 
Trkman, P. (2010), "The critical success factors of business process management", International Journal of Information Management, Vol. 30, No. 2, pp. 125-134.

van den Bergh, J. and Viane, S. (2012), "Promises from SOA: Reengineering a procurement process at Belgacom Mobile - a case study approach", Vol. 18, No. 5, pp. 815-828.

van der Aalst, W.M.P. (2012), "A Decade of Business Process Management Conferences: Personal Reflections on a Developing Discipline", in Barros, A.P., Gal, A. and Kindler, E. (Eds.), Business Process Management - BPM2012, Springer, Tallinn, Estonia, pp. 1-16.

van der Aalst, W.M.P., ter Hofstede, A.H.M. and Weske, M. (2003), "Business process management: A survey", International Conference on Business Process Management (BPM 2003), Berlin, Germany.

Viaene, S., Hertogh, S.d. and Jolyon, O. (2011), "Engaging in turbulent times: Direction setting for business and IT alignment", International Journal of IT, Business Alignment and Governance, Vol. 2, No. 1, pp. 1-15.

Viaene, S., Van den Bergh, J., Schröder-Pander, F. and Mertens, W. (2010), "BPM quo vadis? Challenges and opportunities for business process management", BPTrends, Vol. September 2010, pp. 1-9.

vom Brocke, J., Becker, J., Braccini, A.M., Butleris, R., Hofreiter, B., Kapočius, K., De Marco, M., Schmidt, G., Seidel, S., Simons, A., Skopal, T., Stein, A., Stieglitz, S., Suomi, R., Vossen, G., Winter, R. and Wrycza, S. (2011), "Current and future issues in BPM research: A European perspective from the ERCIS meeting 2010", Communications of the Association for Information Systems, Vol. 28, pp. 393-414.

vom Brocke, J., Petry, M., Sinnl, T., Kristensen, B. and Sonnenberg, C. (2010a), "Global processes and data: The culture journey at Hilti Corporation", in vom Brocke, J. and Rosemann, M. (Eds.), Handbook on business process management: Strategic alignment, governance, people and culture, Springer, Berlin / Heidelberg, pp. 539558.

vom Brocke, J., Recker, J. and Mendling, J. (2010b), "Value-oriented Process Modeling: Integrating Financial Perspectives into Business Process Re-design", Business Process Management Journal, Vol. 16, No. 2, pp. 333-356.

vom Brocke, J. and Rosemann, M. (2013), "Business process management", in Straub, D.W. and Welke, R.J. (Eds.), Encyclopedia of Management, Management Information Systems.

vom Brocke, J., Seidel, S. and Recker, J. (2012), Green business process management: Towards the sustainable enterprise, Springer, Heidelberg.

Willaert, P., van den Bergh, J., Willems, J. and Deschoolmeester, D. (2007), "The processoriented organisation: A holistic view", 5th International Conference on Business Process Management (BPM 2007) Brisbane, Australia. 